\title{
Identification of antifungal peptides produced by Lactobacillus plantarum IS10 grown in the MRS broth
}

\begin{abstract}
The use of secondary metabolites of lactic acid bacteria for preservation of foods is increasingly gaining interest to the food industry to replace synthetic preservatives. In this study, the cell free supernatant containing peptides obtained from Lactobacillus plantarum IS10 was fractionated by size exclusion chromatography using sephadex G-25, and tested against Aspergillus flavus MD3, Penicillium roqueforti MD4 and Eurotium rubrum MD5. Among the fractions, fraction number 10 showed $60 \%$ antifungal activity at a concentration of $0.02 \mathrm{mg}$ peptide $/ \mathrm{mL}$. Four novel peptides out of twenty peptides obtained from fraction 10 were identified and determined by de novo sequencing. Peptide FPSHTGMSVPPP with a net charge +1 , hydrophobicity ratio $58 \%$ and molecular weight of 1253 was further studied. The selected peptide showed a good activity at a concentration of $5 \mathrm{mg} / \mathrm{mL}$ against selected fungi and poor activity at low concentrations. This work indicates that L. plantarum IS10 has the capability of producing peptides which are affective against spoilage fungi.
\end{abstract}

Keyword: Antifungal peptides; Novel peptides; Lactobacillus plantarum; Spoilage fungi 